The Jerry Springer Show as an Emotional Public Sphere

The Jerry Springer Show as an Emotional Public Sphere

Peter Lunt and Paul Stenner

Department of Psychology, University College London, Gower Street, London, WC1E 6BT

p.lunt@ucl.ac.uk, p.stenner@ucl.ac.uk

Acknowledgements: This paper has been presented at seminars in Urbana-

Champaign, LSE, Sussex, City University, Oxford, Bergen, Warwick and Ross Priory where we have received many helpful criticisms and comments. We thank Peter Dahlgren, John Dovey, Josh Gamson, Sonia Livingstone and Graham Murdock for detailed critical feedback on previous versions of the text.

Biographies:

Peter Lunt and Paul Stenner are both social psychologists at University College London. Peter Lunt's research interests are in the psychology of the media audience, consumption and the relationship between social psychology and social theory. His previous publications on talk shows include Talk on Television (with Sonia Livingstone).

Paul Stenner's research interests focus on the social construction of the emotions and the philosophy and history of psychology. He was a member of the Beryl Curt group of critical social psychologists who published Textuality and Tectonics. 


\begin{abstract}
The public sphere debate in social theory has been a topic of considerable interest amongst scholars analysing the talk show genre. Habermas (1989) attached great importance to the potential of rational critical discussion to create consensus and thereby legitimation in democratic society. He was concerned that the media gave a false impression of engagement in a public sphere while managing rights of access and speech in a manner that was inimical to open public discussion. In contrast, cultural commentators on the talk show genre have been impressed by the richness and spontaneity of interactions on the shows, suggesting that they might have a positive role in public participation despite not meeting Habermas's criteria for a public sphere. In consequence, the literature is moving away from the public sphere debate and focussing on issues of voice and expression in analyses of talk shows. This paper, however, makes the argument that many of Habermas's concerns are still highly relevant to the genre. This is demonstrated through an analysis of the Jerry Springer Show. On the surface, this show seems to have little to do with rational critical discussion. The analysis reveals a number of parallels between the conception of the rational critical public sphere and the Jerry Springer show, leading to a revision of the received view of Habermas's work in the analysis of mediated discussion. A range of implications for the mediation of deliberation, participation and expression are explored.
\end{abstract}

Keywords:

Talk shows, emotions, popular culture, public sphere theory, deliberation. 


\section{The Jerry Springer Show as an Emotional Public Sphere}

\section{The Talk Show as Public Sphere}

There is now an established literature in media and communications on the talk show genre (Livingstone and Lunt, 1994; Shattuc, 1997; Gamson, 1998; Dovey, 2000; Tolson, 2001). This literature includes the detailed analysis of interaction on talk shows and discussion of the broader social significance of talk on television. A number of issues have emerged from this research: realism and representation in talk shows; the balance between spontaneity in and control over interactions; the gendered dimensions of the programmes; the role of the hosts and the quality of arguments on the shows. Much of this academic literature argues against the dismissal of talk shows as irrelevant and meaningless 'trash television'. Instead the talk show genre emerges as a context for public participation and debate (Livingstone and Lunt, 1994), as the basis for occasions that afford the expression and exploration of emotions (Shattuc, 1997), and as an opportunity for the expression of voices that are otherwise excluded from the media (Gamson, 1998).

The theoretical background to this work on the talk show centres on Habermas's (1989) conception of the rational critical public sphere. For Habermas, deliberation is an essential requirement of a healthy liberal democracy and he argued that institutional and personal interests potentially pollute the process of public discussion. The formation of consensus, of genuine agreement across lines of difference, requires people to put aside their personal interests and to give up control of public discussion. Habermas conceives of an ideal of disinterested participation in the pursuit of consensus through rational, critical discussion. These public occasions should be neither institutionally controlled nor dominated by personal interests. In this way, the formation of central features of democratic societies such as laws and public opinion can occur in a space of relative protection from individual power plays or the rationalisations specific to particular institutions. These considerations lead Habermas to be sceptical of the potential of media institutions to create the conditions under which public deliberation and opinion formation can take place in a spontaneous and relatively open way. Instead the media are portrayed as creating an illusion of participation. Habermas thus argues that legitimation can only arise in a radical democracy, where processes such as the framing of laws and the formation of public opinion emerge from a genuine, spontaneous and unmediated public deliberation. 
These problems take a particular form in contemporary democracies which are of great scale and complexity. How can deliberation take place without mediation given the logistical problems of coordinating the participation of large, geographically spread, diverse populations?

The literature examining talk shows as public sphere has concentrated on Habermas's arguments concerning the institutionalisation of the political public sphere. In particular, they are a response to Habermas's pessimism resulting from his analysis of the way that public relations and commercialisation have undermined the autonomy of the bourgeois public sphere. Habermas's analysis of the rise and fall of the bourgeois public sphere started with the emergence of a cultural public sphere in Western Europe (his examples are from the England and Germany in the seventeenth century) as an alternative to and a mediator between private and public interests (Holub, 1991). Habermas argues that activity in the cultural public sphere involving discussions of taste and manners and the pleasurable enjoyment of conversation among equals spilled over into the political sphere as it became a forum for the discussion of social, economic and political questions. Habermas's historical story then offers an analysis (inspired by Weber's distinction between rationality and rationalization) of the way that the autonomous, eclectic sphere for public discussion of private interests is threatened by institutionalisation. For Habermas, the ideal typical case of the institutionalisation of the political public sphere was the commercialisation of mass media. An important aspect of this transformation of the context for public discussion (from public spaces to commercially mediated information) was that the relation between private and public interests became too direct, lacking the buffer and the disinterested critical commentary of the public sphere. The result was a crises of legitimation.

Empirical studies of talk shows and audiences take Habermas's (1989) conception of the bourgeois public sphere as its starting point. From there, discussion focuses on such issues as whether talk shows are sufficiently free of institutional control; provide freedom of access and voice; and constitute a viable framework for the formation of public opinion as an emergent consensus concerning issues of the moment. Analysis of the shows reveals that they are characterised by fast moving, chaotic interactions which often 'descend' into quarrels. They do not usually result in conclusions, let alone consensus, are carefully managed by the programme hosts, are scripted and contrived, and place at least as much emphasis on entertainment as upon 
debate, enquiry or discussion. These points suggest a decisive gap between the ideal of a relatively neutral space where consensus can develop out of rational critical discussion and the reality of interactions on talk shows. On balance, the literature concludes that there are reasons to doubt the potential of talk shows to provide the kind of social occasion Habermas that identifies with the public sphere.

Despite these growing misgivings about the relevance of public sphere theory to the analysis of talk shows, a sensibility remains amongst commentators that, despite these limitations, talk shows nevertheless contribute to public participation, deliberation and public expression. Whilst talk shows cannot easily be defended as occasioning autonomous rational critical discussion leading to consensus, they do express something important and characteristic about public opinion and involvement in civic culture. Alternative conceptions of the public sphere that are more compatible with the talk show have been explored. These articulate a more modest and partial role for such programmes in broader processes of democratisation and public participation.

The idea that the talk show might fit an alternative conception of the public sphere has been given impetus by the wide-ranging critique of Habermas' social theory (see the papers in Calhoun, 1993). Livingstone and Lunt (1994) suggest that talk shows are a candidate for an oppositional public sphere, emphasising the expression of interested points of view that give voice to participants' perspectives and aiming at compromise rather than consensus. In such circumstances, the obligations on participants are to express their point of view as clearly and strongly as possible while recognising that there are other interests at stake.

Gamson (1999) suggests moving beyond evaluating talk shows as potential public spheres. Instead, commentators should accept that the talk show provides an institutionally constrained space that nevertheless offers the opportunity for expression of marginal voices that would otherwise not be heard in public. An implication is that the focus of cultural analyses of talk shows should be on questions of voice and expression as moments in a wider process of public deliberation rather than as microcosms of the whole process of deliberation as implied by the public sphere concept. Talk shows are unusual and interesting public spaces: as Livingstone and Lunt (1994) ask, where else can a politician be seen to talk to a housewife on a relatively even footing on a public occasion? Such shows have a potentially democratising aspect, not by virtue of offering opportunities for discussion, but 
through juxtaposition: creating novel combinations of people who normally live separate lives and giving them the opportunity to express their opinions about an issue of topical concern and relevance to them. Even if the more direct claims for the political purposes of the programmes as public spheres are challenged, talk shows can nevertheless be seen to be part of a more general trend towards the democratisation of culture:

"For those who have traditionally been defined as outside of public discussion, whose lives were, until recently, kept private by both choice and coercion people marginalized on the basis of gender, sexual nonconformity, economic status, educational status, physical ability, race, and so on - talk shows have been a crucial site of entry into public view and, at least to some degree, public conversation" (Gamson, 1999, p. 195).

Shattuc (1997) comes to similar conclusions regarding the capacity of talk shows to represent women's experience despite failing to meet the conditions of the bourgeois public sphere.

In addition to these reformulations of the public role of talk on television, a developing literature has emerged on the language and interaction that occurs on talk shows. Analyses focus upon such matters as the role of the host (Tolson, 2001), and the variety of discursive markers of the different roles and phases of the shows. These sociolinguistic studies emphasise the devices deployed in talk shows to construct the sense of liveness in the programmes (Thornborrow, 2001), to frame quasi therapeutic interactions (Brunvatne and Tolson, 2001) and to manage conflict between experts and ordinary people (Wood, 2001). These detailed analyses of talk shows demonstrate the subtle ways in which participation is constructed to draw the studio guests, the hosts and the home audience into a participation framework (Goffman, 1981). These studies indicate that there are important differences between the way that performance and discussion are handled in different talk shows. They also identify the affinities of talk show interactions with everyday conversations, document the ways in which the shows reflect their institutional setting, and analyse how they are produced for an overhearing audience (Tolson, 2001).

A central issue emerging in the talk show literature is that the genre includes a variety of different forms of talk show. The talk show genre is no longer a clear and distinct form but contains at least three show formats. These include shows that focus on public discussion of issues of concern (e.g. Donahue, Kilroy); shows that take an 
explicitly therapeutic approach to personal problems (e.g. Oprah); and shows that focus on conflict and emotive secrets (e.g. The Jerry Springer Show). We could label these public discussion, therapeutic and conflict talk shows. Pretensions to the status of public sphere seem to weaken across these genres and seem least credible in the case of conflict talk shows such as The Jerry Springer Show. This also means that these pretensions have weakened through historical time, since chronologically the public discussion format emerged first and the conflict format last (Shattuc, 1997).

Taken together, these themes in the talk show literature (criticism of the theoretical relevance of the public sphere concept, the close scrutiny of interaction on the programmes, and the variable relevance of the questions of deliberation across exemplars of sub-genre) take commentators away from the abstract concerns of public sphere theory towards a more detailed analysis of the performative aspects of talk on television. These developments contest the continuing relevance of Habermas' (1989) original formulation of public sphere theory because it both misses the details of what is happening on the shows and the significance of the shows as vehicles for the expression of everyday experiences and marginal voices.

\section{Emotions, expression and the public sphere}

In the remainder of this paper, against the grain of the above developments in the talk show literature, we hope to demonstrate the continuing relevance of Habermas's ideas. We do so by examining an example of the genre that seems on the surface clearly to contradict the idea of talk shows as public spheres for rational critical discussion. The Jerry Springer Show is a brash, in-your-face talk show. It seems to revel in the excitable, and is always on the edge of taste and public decency. Participants curse and swear, and physically and verbally threaten one another. Fights break out, in-house bouncers are called in, and the studio audience go wild. This provocative show creates entertainment from the emotions that emerge during the real-time presentation of personal conflict and the on-screen exposure of emotive secrets. The Jerry Springer Show is flagrantly and self-consciously trash television, refusing to take itself seriously, constantly challenging the censors. At its centre is the character of Jerry Springer, who teases, pushes and provokes studio guests into scandalous revelations and accusations. Jerry appears to flirt with explosive situations like the ringmaster of a modern circus of emotional expression. The comparison with freak shows is often made (Dovey, 2000; Gamson, 1998; Springer, 1999). It seems to 
be stretching the point beyond belief to claim that The Jerry Springer Show provides a forum for a public sphere characterised by rational critical discussion.

The argument we wish to make here is that there is still some mileage in the public sphere debate as a frame for analysing talk shows even if we accept that emotional expression and conflict are central features of such programmes. The Jerry Springer Show is an emotional public sphere that parallels the rational critical public sphere in the way that it encourages, manages and reflects upon emotional conflict in a public context. However, we want to be clear from the outset that we are not seeking to claim that The Jerry Springer Show in any straightforward way constitutes a public sphere. Rather we see it as an ironic engagement with the idea of rationalising public discussion and deliberation articulated by Habermas.

One of the reasons we raise these questions is that we see an illuminating conceptual dependency between talk show analysts and Habermas. This occurs despite the formers' critical stance towards Habermas's conception of the public sphere and of its applicability to talk shows. In making the argument that the committed expression of personal views is central to the talk show genre, analysts have reproduced Habermas' distinction between the rational and the emotional. Both the Habermasian inheritance in public sphere theory and the analysis of the talk show as a cultural forum for the expression of marginal voices buy into the same assumption concerning the opposition of rational critical discussion and emotional expression (although they valorise different poles of this opposition). The cultural commentators on the talk show genre share other important assumptions with Habermas' account of the rational, critical public sphere. First, emotionality is linked to questions of authenticity and expression and to questions of identity and is placed in opposition to detached, rational, critical discussion. Secondly they share the assumption that there are normative pressures on emotional expression that create a tension between, on the one hand, giving an opportunity for the expression of deeply felt interests, and on the other, the risk that emotional expression will overflow and disturb the balance of the expression or discussion. Treating emotional expression as important in its place but potentially damaging to the programme parallels Habermas' concerns that the logic of the life-world has the potential to disrupt the procedures of deliberation. The picture that emerges is of the talk show as a fragile social situation in which the emotionally committed expression threatens both the potential for rational critical discussion and the balance in the expression of different points of 
view. Both accounts share the assumption that emotional expression is subordinate to rational critical discussion, reflection or issues of representation and therefore that it must be managed to avoid the disruption of these possibilities. This is not to deny that emotional expression plays an important role in authenticating the accounts of participants on discussion based talk shows (Livingstone and Lunt, 1994) and in revealing the depth of feeling necessary to therapeutic talk shows (Shattuc, 1997). In these examples, however, emotionality is precisely rendered subservient to a predominant communicative agenda (whether 'public discussion based' or 'therapeutic'). Whilst emotional expression plays a key role in these agendas, there remains the constant danger that excesses will disrupt the communicative ends of discussion or therapeutic intervention. The existence of this perceived threat is reflected in a variety of techniques for containing and managing emotional expression on such programmes.

\section{The Jerry Springer Show: an analysis of the construction of emotional conflict.}

Emotional expression on The Jerry Springer Show does not operate either to authenticate the truthfulness of personal accounts or as a potential pollutant of the attempt to discuss life experiences and social issues. Instead, the implicit hierarchy of discussion and emotional expression is reversed. Emotional expression in the form of intense personal conflict or the revelation of secrets is placed centre stage and made the focal point of the programme. In an ironic reversal, rational critical discussion would disrupt the potential for conflict, the revelation of secrets, and the escalation of emotions, and so has to be constrained and managed.

The expression of emotional conflict and the scandalous confessional qualities of The Jerry Springer Show are salient features of the programme and give credence to the view that these shows are 'freakshows' (Dovey, 2000; Gamson, 1998). This appears to be a key difference between The Jerry Springer Show and those examples of the genre that are either more explicitly concerned with the discussion of personal and social issues (Kilroy, Donahue) or have a salient therapeutic dimension (Oprah). However, the moments of conflict, accusation, quarrelling and fighting, although characteristic of The Jerry Springer Show, are only a part of what happens on the show. There is also a lot of talk on the show and that talk has a rhetorical dimension. The host typically starts the show by framing the conflict or issue that will be the focus of the programme. The guests are introduced in an order that reflects their 
relation to the conflict or issue to be revealed. The first guest is usually the complainant (or the bearer of a secret), the second guest is the person who is the object of the complaint or the person to whom the secret is to be revealed. The third guest usually supports the initial claim of the first guest and the final guest is a 'second' for the target of the complaint.

For example, on one programme that focussed on the expression of an emotive secret, Springer starts the show, as he starts the vast majority of his shows, by introducing the problem that will form the topic of the programme. In this case, the problem of how to tell someone that you are in a relationship that it is over because you have proof of their infidelity. The first guest on the show states the claim that he wants to give up his relationship with his fiancée because she has slept with his best friends. Jerry Springer introduces this first guest as a person who has something to say to his fiancée, and elicits the grounds for the complaint using a question and answer dialogue. Springer then introduces the fiancée as the second guest, and she vigorously denies the charge and makes counter charges of her own. Two friends of the initial complainant are then introduced (jointly acting as the third guest in the position of 'second' to the complainant). They claim to have slept with the fiancé. Finally, a fourth guest is introduced who testifies to the faithfulness of the fiancé and offers counter evidence that the complainant has had affairs with women at his place of work. After all the guests have had their say, the host offers an interim summary and then takes contributions from the floor of the studio audience. Members of the studio audience are then invited by the host to give their reactions to what they have just seen and heard. This typically involves taking sides and confronting one or other of the protagonists. This contrasts to their role during the earlier part of the show when they volubly react to every curse from or potential conflict between the protagonists. After these comments and questions have been aired, the host rounds the show off with an 'ethical summary' of the dispute and draws out some general implications and offers some relevant rules of thumb for the conduct of social interaction and the management of relationships.

The setting for the show is a television studio with a 'theatre' set up. The studio audience sit in rows of seats facing a small stage (the set has varied somewhat over series). A number of spatial devices create a distinction between front and back stage. At the beginning of the programme the host appears on camera presenting the broad background to the topic of the show. He addresses this introduction 'offstage' 
(i.e. directly to the home audience) and then invites them to watch the show, thus sanctioning their 'looking in on' the action. After the introduction the host is next shown in the body of the studio audience in a channel that runs through the seats of the studio audience and parallel to the stage. The host walks up and down this channel while questioning and interrogating the guests. A different sense of front and back stage now comes into play as people who are in line to appear on stage are presented via an onscreen inset whilst the current quest appears on stage. They cannot be heard, but their nonverbal responses to the previous guest's contribution can be observed. The first guest is typically already on stage and is introduced and given time to present their claim. This is the quietest part of the show and subsequent guests are given decreasing amounts of time to make their contribution. Through this temporal device, time thus gets condensed over the duration of the programme, increasingly the probability of a build up of tension around the proceedings. Another important feature of the programmes are the bouncers. These are off duty Chicago cops who lurk around the edges of the stage and are ready to intervene if physical confrontation breaks out between the guests (this occasionally involves members of the studio audience too). The action of the bouncers is worthy of note. Their actions are proportionate to the degree of physical threat at play. For example, if a particular guest is getting agitated, standing up and moving towards another guest (maybe finger pointing or shouting) then a bouncer will position himself between the guests and try to direct the guest back to their seat. If two guests are squaring up but not throwing punches then the bouncers get in between the protagonists and separate them. If there is a more violent confrontation (punching, kicking, biting) then the protagonists are wrestled to the floor by the bouncers and held until they agree to calm down. The bouncers therefore provide the opportunity for violent physical aggression in a context where the protagonists know that they will not be able to do too much damage to each other. It is also clear that the model of intervention is in the form of a barrier or an embrace, symbolising an act of caring control on behalf of the show that allows the guests to emotionally 'let go'. The studio audience act both as a barometer of the affective climate in the studio, and as its amplifier. As the show proceeds they get more and more excited, breaking out into howls, shouts and screams proportionate to the level of emotional conflict between the guests, who are in turn thereby incited to further emotional escalation. These design features of the show combine to maximise the likelihood of extreme expressions of emotional conflict. 
Throughout their turns, the guests quarrel, use strong language, shout at and get angry at each other. Yet, at the same time, they act in a predictable way by entering in order and on cue, answering the host's questions, and deploying their arguments in a manner that is consistent with their roles in the debate. This ordering of the guests' appearances on the show clearly follows the traditional ordering of a debate (Walton, 1989). The host's role is similar to that of the chair of a debate in framing the question for debate and managing the turn taking of the speakers, taking contributions from the floor and providing a summary. All this follows the structure of a debate from the chair's introduction, through primary and secondary motions and counters, to the taking of points from the floor and the summing up. The only thing that is missing is the vote at the end of the debate.

The host does more than introduce the parties to the debates. He is active in managing the contributions of participants using a variety of elicitation techniques to facilitate the guests' contributions, and using a range of methods to contest the accounts offered by the guests. In particular, he asks for further clarification of the description of events, he sometimes questions the rights of participants to talk or to act in the way that they do, and he questions the sincerity of some contributions. Through these aspects of his performance, the host is acting more like the head of a public enquiry than the chair of a debate (Walton, 1989). As an argument context, therefore, The Jerry Springer Show combines the debate form with some of the methods of a public enquiry. The adoption of these argument contexts (debate and enquiry) places obligations on all the participants, structuring them into a participation framework with a variety of communicative roles (Goffman, 1981). Yet, as we have seen, these organisational features of the programme do not preclude the expression of emotional conflict, quarrels, wild accusations and, sometimes, physical conflict. The expression of emotional conflict and the enquiry into human conduct are not in opposition but complement each other, or at least run in parallel. The programmes weave together emotional expression and argumentation, overlaying the argument contexts of debate and enquiry onto a range of devices that enable the expression and management of emotional conflict. We interpret these programmes as an assemblage that combines expression of deeply felt interests with the scrutiny of arguments, the responses of the studio audience and a summary by the host (Callon, 1986). The programme attempts to meet the demands of both the expression of interests and disinterested enquiry, reflecting the contradictory demands of private and public 
interest. However, these different elements of the show are not thematically or narratively organised, but are woven together in the interaction between the host and the guests. The activities of the host and the ordering of discussion and interaction in The Jerry Springer Show allow for a simultaneous combination of a distilled emotional expression, on the one hand, and a public interrogation of the claims, counter claims and actions of the protagonists, on the other.

\section{Parallels between The Jerry Springer Show and the 'public sphere' concept}

Our analysis of The Jerry Springer Show suggests the possibility that the programme does not try, and subsequently fail, to produce a public sphere. Instead, it combines some of the elements of emotional engagement, excitability and interest that are the provenance of the cultural public sphere, with some of the strictures of rational critical discussion that are characteristic of the political public sphere. In The Jerry Springer Show, the problematic relation between the expression of personal interest and the question of the public good are handled by directly interweaving these themes in an interaction sequence of questioning and answering, conflicted interaction and commentary.

An important aspect of the bourgeois public sphere is that it constituted an elision of disinterest. People would gather, conduct their conversations and then 'return' to their private and public lives. Public spheres therefore have a temporary, liminal quality that distinguishes them both from an institutional context and from the private spaces of the lifeworld, thereby enabling relatively rational and impartial discussions of cultural and political issues. Participants on The Jerry Springer Show are, similarly, 'famous for fifteen minutes' and participate in a public occasion that is a world apart from their everyday lives. There is a parallel with Habermas' conception that public discussion has the potential to resolve differences and facilitate reflection. However, Habermas saw a problem in the development of the press which initially serviced the needs of the cultural and emergent political public spheres, but which was gradually commercialised. Through its commercialisation it began to represent public opinion rather than to provide a free forum for the emergence of public opinion. The mass media, under this interpretation, are so polluted by the twin needs of promotion and the need to create a readership that they cease to provide a relatively neutral resource for the development of public opinion. Publicity of private and public interests became the structuring forces in mass communication, which crowded out 
the potential for a mass mediated public sphere. A central question for our account of The Jerry Springer Show is whether the public expressions of conflict and emotive secrets are to be understood entirely as the promotion of private interests coinciding with the needs of the producers of entertainment spectacles. Our emphasis suggests that these are two different dimensions of the programme that sit side by side rather than crowding each other out in the way suggested by Habermas's analysis.

Behind our analysis of The Jerry Springer Show as an emotional public sphere is the idea that contemporary society is so complex, so dependent on social institutions and so grounded in individualism that Habermas's insistence on unmediated, non-institutionalised and yet public occasions at the centre of public life seems idealistic in the extreme. Habermas draws a strong analytic distinction between an idealised public sphere and a extreme case formulation of the mutual pollution of private and public interests. His is a classic Marxist analysis that emphasises the conflictual aspects of relations in public, which require special conditions for the possibility of synthesis. Essentially, Habermas, in his initial formulation of public sphere theory, suggests the need for an ideal set of conditions that allow for both the expression of rights (based on rights of access and rights of speech) and the formation of a body politic or a sovereign public. Habermas has a heightened sensibility for the potential conflict between these two demands. He sees institutional control and the expression of private interests as undermining the conditions for synthesis between rights and the formation of principled consensus. In contrast, our analysis of The Jerry Springer Show suggests an emergent process that links personal troubles to social issues through concrete, institutionally controlled and privately motivated social occasions. Elements of the conditions called for by Habermas are present alongside and amongst the conditions he regards as inimical to the formation of a synthetic fusion of rights and a sovereign public.

Another important assumption of the public sphere concept is that it offers an opportunity for communication across social divisions. Voices that are repressed because they are not powerful enough either in terms of private status or public standing are placed on an equal footing with the voices of established power. This parallels a number of features of the Springer Show. Issues that are part of everyday life are given an airing however gruesome the details. Conduct that would usually lead to exclusion from the media (vernacular language, swearing, threatening) are accepted as part of the difficulty of bringing emotional issues out in public. People 
who are usually excluded on the grounds of looks, linguistic ability or social class position are given a space on the programme. There is, however, a tension between the idea that this is one of the few places that people in such circumstances can get access to the media, and the idea that they thereby become an object of fascination for viewers of a modern-day freak show (Dovey, 2000). The programme does make the democratising move of making the life world visible so that we get to see the social world warts and all, which may well be a sobering experience. At the very least the Springer show makes things visible that have been hidden before, and gives a voice to many who would otherwise not be heard in public.

To summarise the argument so far, we have seen that there has been a move away from analysing talk shows as potential public spheres in the talk show literature. The analysis we have presented suggests that The Jerry Springer Show inverts the principles of the bourgeois public sphere. Rather than avoiding the potentially polluting effects of personal and institutional interest, The Jerry Springer Show embraces them and inverts the hierarchy between argument and feeling. We also suggested a variety of parallels between Habermas's conception of the bourgeois public sphere and the mediation of the expression of conflict in The Jerry Springer Show. At stake are two notions of the mediation of public deliberation and the attendant problems of providing legitimation that fuses the requirements of rights based on freedom of expression with the need to form agreements and formulate principled decisions. Habermas argues that this fusion can only take place if a 'strange situation' occurs where personal and institutional interests are set aside and agreement is sought through the interaction of free individuals. In contrast, The Jerry Springer Show articulates the view that public deliberation can fuse the demands of giving equal rights of expression with the possibility of commentary and reflection by embracing both rather than outlawing them. This analysis suggests that in the talk show literature the public sphere concept has been taken too literally - and that what is still relevant in Habermas' work are issues of rights, norms, public expression and deliberation. His elegant summary of these issues in relation to the 'public sphere' concept does not translate to the talk show, but, nevertheless, our analysis of the talk show keys into the same underlying theoretical issues that motivated Habermas' account of the public sphere. Habermas has since reformulated and developed his ideas on deliberation and on the relation between public participation and the institutionalisation and commercialisation of public life. We pick out three 
developments in Habermas' work here, all of which elaborate on his initial account of the bourgeois public sphere and broaden out his consideration of the relationship between deliberation and legitimation in complex, pluralistic societies.

\section{Beyond the public sphere: discourse ethics, communicative action and between}

\section{facts and norms}

Habermas has developed his thinking concerning questions of public deliberation significantly since his first account, written in the 1960s. In the remainder of the paper we will relate our analysis of The Jerry Springer Show to Habermas's work on discourse ethics, his theory of communicative action (1984) and his recent work on the relation between substantive and formal rationality in Between Facts and Norms (Habermas, 1996). In the work on discourse ethics and communicative action the public sphere debate is in the background. However, in Between Facts and Norms Habermas returns to the public sphere debate and particularly to questions of how institutional discourses relate to the problematic relation between two routes to legitimation, one based on norms and the other grounded in the concrete practicalities of institutions. As we have already indicated and hope to demonstrate further, these later writings of Habermas on questions of deliberation present a useful way of thinking about The Jerry Springer Show.

\section{The Discourse Ethics of The Jerry Springer Show.}

One aspect of the role of the host in the Jerry Springer show is to elicit and interrogate the personal stories, feelings and secrets of the protagonists. We have suggested that this is organised through the creation of a hybrid argument context that combines elements of debate and public inquiry with opportunities for the expression of conflict and emotive secrets. These interactions between hosts and protagonists can be analysed using the categories of Habermas's discourse ethics. Habermas distinguishes between four types of validity claim implicitly made by participants in free and open dialogue aimed at reaching a mutual understanding (Outhwaite, 1994, p. 40). The claims are promissory in the sense that they are not expected to be backed up or supported during the interaction itself, but are implicit claims that participants are able to account for in principle (or if they were called upon to justify what they were saying). The categories of claims that Habermas distinguishes are: meaning, sincerity, appropriateness and truthfulness. In the example from the Springer show above, when the claimant says that his fiancé has been sleeping around he makes an implicit set of pragmatic claims to the effect that he is communicating clearly what his 
accusation is, that he has the right to make such an accusation, that he is sincere in wanting to make the accusation and that, as far as he knows, this is a truthful accusation. In The Jerry Springer Show, the host, the other protagonists and the studio audience all question the claims made in the programme along these lines. The host often tests the meaning of statements made or seeks clarifications ('what do you mean by that'?), he often tests the sincerity of statements ('you can't be serious'?) and he often questions the right of the person to say something ('is that the kind of thing a mother should say to her daughter'?). However, the host does not challenge the truthfulness of statements made in the programme. The protagonists and studio audience do make challenges about the truthfulness of the claims made ('you're a liar'). This distribution of challenges to the pragmatic assumptions of claims on the Jerry Springer Show is interesting as it suggests that the host is seeking to prompt and display the stories and claims of protagonists and leaving the question of the truthfulness of the claims to one side. As with the structuring of the argument context discussed above, the cut and thrust of exchanges in The Jerry Springer Show masks a thorough going examination of the claims and counter claims made in the programme. All of this goes on along side the emotional exchanges in the programmes. As a form of mediated public participation the show works by setting a scene with participants, props and a script; managing the taking of turns and the interplay between guests and the studio audience; and providing a commentary.

\section{Communicative action and the Jerry Springer Show}

A central theme that runs through Habermas's work is that distorted communication threatens procedures of legitimation in modern societies. In the context of The Jerry Springer Show this would take the form of the discourse of debate and commentary masking an entertaining spectacle that merely provides an opportunity for the expression of personal interest. The Jerry Springer Show makes a number of similar working assumptions about what causes the emotional conflicts expressed or secrets revealed on the programme. The programme presents emotional problems as resulting from distorted communication in relationships. From the host's introduction, through the expression of conflict and the revealing of secrets, to the public interrogation of the guests, and finally to Springer's ethical summary runs a theme that people cannot find the words to speak to each other in their private lives. Consequently, what they need, as a form of intervention, is to bring their private problems into the public domain: to get the issue out into the open, to exteriorise it 
through performance and to expose it to public scrutiny. Personal relationships are represented as a private entanglement that participants lack the competencies to resolve, suggesting an historically emergent crisis of the emotions (Mestrovic, 1997). This parallels Habermas's (1984) argument that the logic of the lifeworld operates according to a variety of rationalities including the instrumental (means-end), those concerned with face (the construction and preservation of personal identity), and the normative (acting according to what is socially sanctioned). Habermas argues that only by subsuming these ways of dealing with others within a free, public, conversation aimed at mutual understanding can communicative action unfettered by private interest emerge. An accumulated effect of the lack of distance between public and private realms is that issues that 'pollute' public life such as personal conflicts and emotive secrets need public expression and interrogation to release them from the constraints of self-presentation. The Springer Show makes similar assumptions about emotional problems: the problem in everyday life is that people are unable to overcome their tendencies to objectify others as means to ends; they are trapped by a need to construct a positive self-identity; their normative conceptions of what is acceptable interpersonal behaviour constrain them.

The accumulated effects of the commercialisation of feeling (Hochschild, 1983 ) and the institutionalisation of public expression, coupled with the pollution of rationality by issues of identity and normativity, produce distorted forms of communication within the lifeworld. These require the oxygen of publicity.

\section{The moral concerns of the Jerry Springer Show}

The Springer Show has the appearance of being immoral or sinful. For example, people admit to having affairs, hating the people they are in relationships with, and acting in ways that are aggressive or scurrilous both on and off the programme. Nevertheless, the programmes incorporate moral and ethical dimensions at various points. Moral norms are used as a way of interrogating claims and accusing people ('you're a whore'). The host uses normative moral conceptions to challenge guests' accounts, routinely contesting the ethical stance of the guests. The opinions sought from the studio audience often take the form of moral questioning or indignation, and Springer rounds of the show with an ethical summary ("what have we learned today'?). There is, therefore, a sense that these programmes, whilst primarily organised to produce emotional conflict and the public expression of emotive secrets, at the same time constitute a reflection on character and conduct in contemporary life. 
This mirrors one of Habermas' (1996) themes that communicative action gets its significance from the way that it combines engagement with the facticity of everyday life with transcendent moral themes. What is significant about The Jerry Springer Show is that this kind of fusion of issues of rights and principles is worked through as a performance in an institutional context.

Common criticisms of Habermas's early writing on the public sphere involve either accusing him of working with a historical fiction, or contrasting his historical conception with putative public spheres that conspicuously fail to meet his criteria (Calhoun, 1995). Habermas gives an extended reply to these criticisms in Between Facts and Norms in which he draws upon his conceptions of 'discourse ethics' and 'communicative action' to present an analysis of the grounding of the law in democracy and the potential of the law to legitimate governance in secular society. In all this, Habermas is arguing against two trends in cultural analysis: the emphasis on the radically local formation of truth and right, and the idea of specialist subsystems of society that operate without reference to human rights (postmodernism and systems theory). The idea that a principled resolution is possible even in the face of conflicts of interest has been a theme underlying all of Habermas' work. The Jerry Springer Show represents a similar set of problematics, giving space for the communication of idiosyncratic rights of expression and affording public reaction, reflection and commentary. The Jerry Springer Show demonstrates the implications of the radical pluralism that results from granting open rights to speak by allowing differences to unfold in emotional conflict, and then offers a public reaction and commentary on these events.

At another level the programme presents and examines problems in the realm of convoluted personal politics. The issue that is at stake here is the problem of individualism and the lessening of the social ties of family, friends and moral advisors. Consequently, in contemporary life individuals are left to their own devices to sort out difficult issues of feeling and morality (Giddens, 1991). The rise of individualism and decreased sociality (at least in relation to traditional role relationships) is also one of the motivating ideas underpinning Habermas' work on the public sphere, discourse ethics and communicative action. Habermas and the Jerry Springer Show are responding to very similar concerns about the consequences of individualism. In this context, the relation between human rights and the right to speak becomes paramount. Habermas was concerned about the way that certain 
voices are systematically under represented in institutionally managed public spaces or polluted by the corroding influence of personal interest. The Jerry Springer Show offers a view of the potential for combining emotional expression and discussion in a process of public reflection. As such, it is an example of the interesting ways in which a collectivity may be formed pragmatically, through elision rather than through the formation of consensus. To use a Durkheimian (1965) notion, The Jerry Springer Show operates as a vehicle for social currents (rather than collective representations) that operate through argument but also through collective effervescence (rather than through rational-critical discussion). The combination of reflection and expression is the key to understanding the potential value of this kind of talk on television.

A further relevant dimension of Habermas's theory of communicative action is the emphasis on procedural rationality as a way of overcoming distorted communication resulting from the domination of either substantive interests or rationalisation. We suggest that The Jerry Springer Show, along with much of the reality TV genre, works as a kind of idealised, distilled, simulation of the complex connections between private problems and public concerns (Turner, 1999). It does not make the traditional claim of factual broadcasting (that it produces a picture of reality) except in the very specialised sense that it offers a particular, distilled and controlled demonstration of interactions that typify everyday problems. Rather than being an ideal speech situation, The Jerry Springer Show is an ideal conflict situation. The mechanics of the programme (including the hosts guidance of the sequence of interaction, the studio audience's 'encouragement' of the guests' excesses, and the presence of the bouncers who stop any real harm coming to anyone) mean that the show is not a shadowy representation of a 'real' public occasion, but a carefully crafted occasion in its own right. The show is 'ideal' in the sense of deploying a setting, props, a participation framework, and an argument context that creates ideal circumstances for the public expression of emotional conflict. This emphasis on the performative is another parallel between Habermas and the Jerry Springer Show. Habermas has an ideal conception of the public sphere grounded in the pragmatic assumptions underlying the performance of conversation. He argued that it was only through the accomplishment of free conversation that rational discussion and reflection could emerge. Springer, similarly, puts the emphasis on enactment combining the expression of emotional conflict with public enquiry and ethical commentary. 


\section{Discontinuities between public sphere theory and the Jerry Springer Show}

Although these are suggestive parallels between Habermas's concerns and the structuring of The Jerry Springer Show there are also some stark differences between them. For example, the public sphere is an ideal speech situation in which the force of argument prevails, whereas The Jerry Springer Show is an ideal conflict situation in which the force of the spectacular succeeds. There is also a difference in tone such that the serious intentions of rational critical discussion are apparently at odds with the spectacular and ironic playfulness of the Springer Show. The display and interrogation of emotional conflict and emotive secrets may require the softening influence of irony and playfulness. This may be antithetical to discussion, but facilitates the expression of deep differences. There might be a functional equivalence between the attempt to create a serious context for rational critical discussion and a playful context for emotional expression. This point also underlines the different role that entertainment plays in different talk shows. Entertainment potentially gets in the way of discussion, but it smoothes the path of emotional expression and conflict.

There also seems to be a difference between a procedural logic aimed at providing a public space for political engagement and a space that encourages the expression of privately held antagonisms and secrets. However, this difference brings out an important lacuna in Habermas's conception of deliberation through rational critical discussion. As a number of commentators have suggested (Fraser,1993; Bohman, 2000; Gamson, 1998, 1999), public participation and deliberation in complex pluralistic societies are likely to involve strongly held emotions that need to be faced, expressed and reflected upon. The Jerry Springer Show is a metaphor for the complexities of the relation between the emotions of social and political involvement and their connection to deliberation and public reflection.

\section{Conclusions}

This paper began with a review of the arguments concerning the public sphere as a framework for analysing the talk show genre. We noted a shift in the literature away from using Habermas's conception of the rational critical public sphere, and towards a focus on issues of voice, the expression of marginal experiences and identities. On the surface, The Jerry Springer Show appears to contradict the requirements for rational critical discussion and to illustrate the way that emotional expression and personal interest are the key features of talk shows. In contrast, we 
have identified a number of parallels between Habermas' proposals for rational critical discussion and the organising features of The Jerry Springer Show.

What emerges is an argument that public deliberation can produce knowledge, testimony and reflection not by attempting a realistic representation of events or by building a consensus in opinion, but by setting up a set of circumstances that afford a mixture of emotional expression, argument, reflection and ethical summary. The Jerry Springer Show, rather than attempting to control and exclude emotional expression from public participation confronts the problem of communication in emotionally laden contexts. Under this interpretation, a rarefied, distilled expression of emotions can emerge through the oxygen of publicity.

There are implications for the argument that Talk Shows, as managed shows, are under the control of the media and therefore cannot be understood as public spheres. Institutional control over the circumstances of participation has, following Habermas (1989) been regarded as inimical to public discussion and debate. At the same time, the identity-based logic of the life-world, organised around normative and self-presentational dimensions of everyday social life potentially pollutes the possibilities for detached, rational discussion. Hence, the argument for a space that is neither subject to institutional control nor overtaken by the politics of everyday life, and the concern over features of television programmes that either manage discussion or dissolve into dispute. Our analysis suggests that The Jerry Springer Show is both highly structured and tending towards dispute. The parallels between the rational critical public sphere and the show suggest that for certain strongly felt issues characterised by extreme conflict, we can not rely on the spontaneous effects of the pragmatics of conversation. Equally, we cannot hope for much if we just leave people to their own devices. The Jerry Springer Show emerges as a model of a structured context that combines 'letting go' (the expression of deep feelings and concerns in a public context) with reflection and commentary. The staging of the programme is essential to this process rather than a hindrance to it. The programme (to paraphrase Elias, 1994) enables a controlled decontrolling of emotional controls. These arguments are important given some of the ideas that have developed in the sociology of the emotions (Mestrovic, 1997; Jameson, 1991) that suggest that we are living in an 'affective climate' (Stenner, in press) characterised by thin collectivity and cool emotional expression (Turner, 1999). Against that background The Jerry Springer 
Show presents an interesting counter balance: a managed space that engages with deeply held emotional commitments that are central to participants' identities.

This analysis also raises issues concerning the relationship between the scripted or ritual aspects of communication and spontaneity. Scripting emerges not as the opposite of spontaneity but its complement. Livingstone and Lunt (1994) suggest that talk shows work in a self referential way and that because the programmes are recorded as live and the action all takes place within the studio there is neither time nor resources to explore the background to issues and the complexity of the accounts being offered in the programme. The resources that are available to the programme are the interactions that occur within the programme itself, and the reflections offered immediately on those interactions. Similar issues emerge in the analysis of The Jerry Springer Show as an emotional public sphere. Much of the potential of the programme comes from the carefully managed and crafted creation of emotional expression and the surrounding commentaries and reflections. Perhaps the talk show should not be viewed and evaluated as providing a public sphere, but as one part of the mediation of public expression, reflection and deliberation. The Jerry Springer Show is a controlled demonstration of the way that human beings react when given the opportunity to express what has been difficult to express in their everyday lives. This is coupled with the immediate reaction of a sample of the public who, along with the host, try to make sense of issues that are relevant to us all but experienced in the privacy of our relationships.

This analysis allows us to finesse the two responses in the talk show literature: one emphasising the idea of talk shows as oppositional public spheres, and the other as opportunities for strategic expression of marginalized voices. A difference between the 'oppositional public sphere' proponents, and the 'voice and expression' proponents is that the former continue to think of talk shows as offering a public sphere (albeit one entirely antithetical to Habermas), whilst the latter do not. While for Habermas the public sphere was a site for the generation of rational consensus, for the proponents of the oppositional public sphere they constitute a site for the generation and presentation of arguments and positions. Perhaps the justification for continuing to think of talk shows as part of the public sphere is the idea that these arguments and positions will be digested and considered by the viewing public (in which case these should surely be considered the public sphere). 
However, we have demonstrated that even if we abandon with Habermas the idea of finding a public sphere in the mass media we still find his notions useful, albeit in a highly paradoxical way, for making sense of talk shows as a form of public participation. Running parallel to Habermas' ideal, Springer represents a kind of parody of the rational public sphere. A paradoxical inversion, we might say, much as in Bahktin's (1981) concept of the carnivalesque as an inversion of ordinary life. Habermas's concepts work as analytic devices that help us to understand the show, but in the opposite direction to that intended in his theory of the public sphere. A way of thinking about this is to say that Springer takes the sins of the mass media upon himself. Those sins include partisanship, partiality and the dominance of entertainment over information. In short, all of the things which academics have suspected talk shows of doing (for example, suspicion that entertainment is the main agenda; that the whole thing is rigged) are made patent and displayed unashamedly. Springer deconstructs the possibility of a mass media public sphere far more effectively than any academic commentator, such that commentary on it becomes redundant, almost an embarrassment. It is redundant to point out that this show is 'in fact' a carefully constructed and skilfully orchestrated façade that only 'pretends' to be a public sphere. Springer has done that for us, but it is precisely in this that he does us a service. Paradoxically, we find in the show a means to overcome the perpetual 'critical' distinction between 'construction' and 'reality'. The effects produced are real because they are constructed.

Finally, this analysis suggests a reorientation of the discussion of Habermas's work in the talk show literature. The focus has been on his initial formulation of public sphere theory but, as we have seen, there are various ways to renew the engagement with Habermas's thinking. Firstly, recovering the concept of the 'cultural public sphere' from Habermas's early work. Second, the application of ideas from Habermas's later work on discourse ethics and communicative action provide valuable concepts for interpreting what is going on in The Jerry Springer Show. Thirdly, Habermas's more recent efforts to accommodate the tension between political and private autonomy through a procedural account of the formation and legitimation of law in a radical democratic state open up a possibility of an analysis of talk shows as linking individual problems to social issues. Habermas was principally concerned with the law and with resolving the tensions between rights based and idealised foundations for the legitimate construction of law (which he accomplished 
by arguing for a hierarchy of communicative actions). The exploration of such practical questions inevitably raises more abstract ethical questions of how we can manage to accommodate strongly felt differences while also hoping for a principled justification for social arrangements. Habermas opens up the possibility of an important, although partial role for institutional arrangements and procedures in the production of legitimate, publicly acceptable binding principles that implicate both institutional representations of popular sovereignty and the expression of individual autonomy. This move also has the benefit of recovering the underlying reasons for scholarly interest in talk shows as putative public spheres: that the shows link personal troubles to social issues in a way that engages both the identity or private autonomy of individual participants and questions related to participation in civic society opening up the possibility of a discussion of obligations and an exploration of the fairness of these engagements.

\section{References}

Bohman, J. (2000) Public Deliberation: Pluralism, Complexity, and Democracy. Cambridge Mass.: MIT press.

Brunvatne, R. \& Tolson, A. (2001) 'It makes it okay to cry: two types of 'therapy talk' in TV talk shows' pp. 139-154 in Tolson, A. (Ed.) Television Talk Shows: Discourse, Performance, Spectacle. Mahwah, N.J.: Lawrence Erlbaum.

Calhoun, C. (1993) Habermas and the Public Sphere. Cambridge, Mass.: MIT Press. Dovey, J. (2000). Freakshows: First Person Media and Factual Television. London: Pluto Press.

Callon, M. (1986) 'Some Elements in a Sociology of Translation: Domestication of the Scallops and Fishermen of St. Briec Bay’ pp.196-233 in J. Law (Ed.) Power, Action and Belief. London: Routledge.

Durkheim, E. (1965). The Elementary Forms of Religious Life. New York: Free Press. Elias, N. (1994) The Civilizing Process. Oxford: Blackwell.

Gamson, J. (1998) Freaks Talk Back: Tabloid Talk Shows and Sexual Nonconformity.

Chicago: University of Chicago Press.

Gamson, J. (1999). 'Taking the Talk Show Challenge: Television, Emotion, and Public Spheres. Constellations, 6(2), 190-205.

Giddens, A. (1991). Modernity and Self-Identity: Self and Society in the Late Modern Age. Cambridge: Polity Press. 
Goffman, E. (1981) Forms of Talk. Oxford : Blackwell.

Habermas, J. (1989) The Structural Transformation of the Public Sphere. Cambridge, Mass.: MIT Press.

Habermas, J. (1984, 1987) The Theory of Communicative Action, volumes I and II.

Cambridge: Polity Press.

Habermas, J. (1996) Between Facts and Norms. Cambridge: Polity Press.

Holub, C. (1991) Jurgen Habermas: Critic in the Public Sphere. London: Routledge

Hochschild, A. R. (1983). The Managed Heart: Commercialization of Human

Feeling. Berkeley: University of California Press.

Hutchby, I. (2001) 'Confrontation as a Spectacle: the Argumentative Frame of the Ricki Lake show' pp. 155-172 in Tolson, A. (Ed.) Television Talk Shows :

discourse, performance, spectacle. Mahwah, N.J.: Lawrence Erlbaum.

Jameson, F. (1991) Postmodernism or The Cultural Logic of Late Capitalism.

London: Verso.

Livingstone, S. and Lunt, P. (1994) Talk on Television. London: Routledge.

Mestrovic, S. (1997) Postemotional Society. London: Sage.

Myers, G. (2001) "I'm Out of It; You Guys Argue": making an issue of it on The Jerry Springer Show pp. 173--192 in A. Tolson, (Ed.) Television Talk Shows :

Discourse, Performance, Spectacle. Mahwah, N.J.: Lawrence Erlbaum.

Outhwaite, W. (1994). Habermas: a Critical Introduction. Cambridge: Polity.

Shattuc, J. M. (1997) The Talking Cure: TV Talk Shows and Women. London:

Routledge.

Stenner, P. (in press) 'Is autopoietic systems theory alexithymic? Luhmann and the socio-psychology of emotions'. SozialSysteme.

Thornborrow, J. (2001) 'Has It Ever Happened to You?: Talk Show Stories as Mediated Performance' pp. 117-137 In Tolson, A. (Ed.) Television Talk Shows : discourse, performance, spectacle. Mahwah, N.J.: Lawrence Erlbaum.

Tolson, A. (2001) Television Talk Shows: Discourse, Performance, Spectacle.

Mahwah, N.J.: Lawrence Erlbaum.

Turner, B. S. (1999). 'McCitizens: Risk, Coolness and Irony in Contemporary Politics' pp. 83--100 in Smart, B. Resisting McDonaldization. London: Sage

Publications.

Walton, D. (1989). Informal Logic: a Handbook for Critical Argumentation.

Cambridge: CUP. 
The Jerry Springer Show as an Emotional Public Sphere

Wood, H. (2001) "'No YOU Rioted!": the pursuit of conflict in the management of "lay" and "expert" discourses on. Kilroy' pp. 65--88 in A. Tolson (Ed.) Television

Talk Shows : Discourse, Performance, Spectacle. Mahwah, N.J.: Lawrence Erlbaum. 